\title{
Progressive Central Nervous System Neoplasm
}

National Cancer Institute

\section{Source}

National Cancer Institute. Progressive Central Nervous System Neoplasm. NCI

Thesaurus. Code C147113.

A central nervous system neoplasm that is increasing in scope or severity. 